\title{
Angiosarcoma of the Thyroid Gland: A Case Report
}

\author{
Fouad Zouaidia ${ }^{\mathrm{a}, \mathrm{b}}$, Ahmed Jahid ${ }^{\mathrm{a}}$, Hafsa Elouazzani ${ }^{\mathrm{a}}$, Leila Laraki ${ }^{\mathrm{a}}$, \\ Zakiya Bernoussi ${ }^{\mathrm{a}}$, Fatima Mansouri ${ }^{\mathrm{a}}$, Najat Mahassini ${ }^{\mathrm{a}}$
}

\begin{abstract}
The authors described a case of rare histological type of primary thyroid tumour: angiosarcoma. We report a case of 37 years old female who presented with the mass in the anterior of the neck that had been rapidly growing for several months. Scintigraphy showed a cold nodule in the left lobe of the thyroid. The patient underwent subtotal thyroidectomy. The cut surface showed a bulging solid grey hemorrhagic mass, measuring $6.5 \mathrm{~cm}$ at the lower pole of the left lobe. Microscopically a poorly differentiated highly desmoplastic polymorphocellular tumour. Immunohistochemically, the cells showed immunoreactivity for endothelial markers CD31, CD34, Facor VIII related antigen and immunonegativity for epithelial markers including pancytokeratin, epithelial membrane antigen and thyroglobulin. Radiotherapy was applied. The patient was alive after a follow up of five months.
\end{abstract}

Keywords: Thyroid; Angiosarcoma; Pathology

\section{Introduction}

Angiosarcoma, made up of malignant endothelial structures, represents a rare and aggressive connective tissue tumour of the thyroid. It rarely occurs in that organ and most of these occur mainly in patients from the mountainous Alpine regions. It is most prevalent in Switzerland where it constitutes $4 \%$ to $5 \%$ [1].

Angiosarcoma of the thyroid has long been a controversial entity because some authors believe that it is a distinct

\footnotetext{
Manuscrit accepted for publication May 20, 2010

${ }^{\text {a}}$ Department of Pathology, Ibn Sina Hospital, Rabat, Morocco

${ }^{\mathrm{b}}$ Corresponding author: Department of pathology, Ibn Sina hospital; Rabat, Morocco. Email: fouad_z@hotmail.com
}

doi: $10.4021 / \mathrm{jmc} 2010.07 .107 \mathrm{e}$ entity of endothelial origin but others consider it to be a variant of undifferentiated carcinoma. So the differential diagnosis includes pseudoangiosarcomatous carcinoma of the thyroid [2].

We describe a case of angiosarcoma of the thyroid. To confirm the nature of the present tumour, immunohistochemistry examination was done.

\section{Case Report}

A 37 years old female presented with the mass in the anterior of the neck that had been rapidly growing for several months. Scintigraphy showed a cold nodule in the left lobe of the thyroid. The results of thyroid function tests were within the normal range.

The patient underwent subtotal resection of the left thyroid lobe. The cut surface showed a bulging solid grey hemorrhagic mass, measuring $6.5 \mathrm{~cm}$ at the lower pole of the left lobe (Fig. 1). The specimen was fixed in10 neutral formalin and then embedded in paraffin. Microscopically it was a poorly differentiated highly desmoplastic polymorphocellular tumour (Fig. 2, 3).

Immunochemistry was done by avidin biotin peroxydase complex method. Antibodies against the following antigens were used. Immunohistochemically, the cells showed immunoreactivity for endothelial markers CD31, CD34 (Fig. 4),

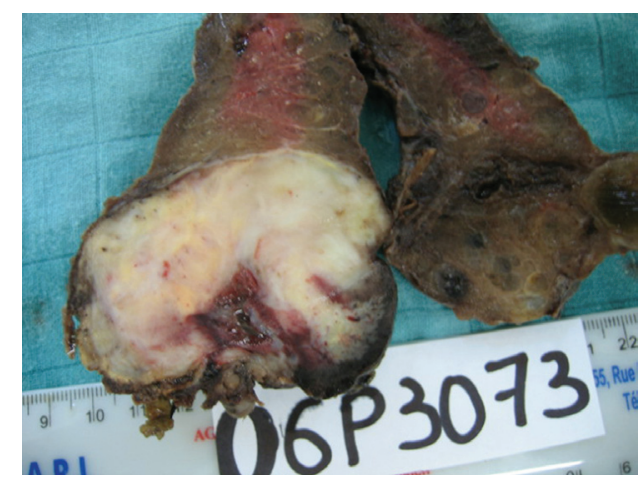

Figure 1. The cut surface of the thyroid shows a well demarcated bulging. 


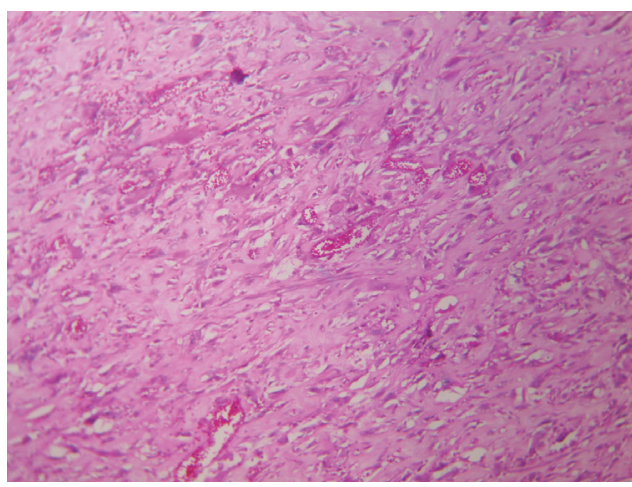

Figure 2. Spindle cell proliferation (HE Stain x 100).

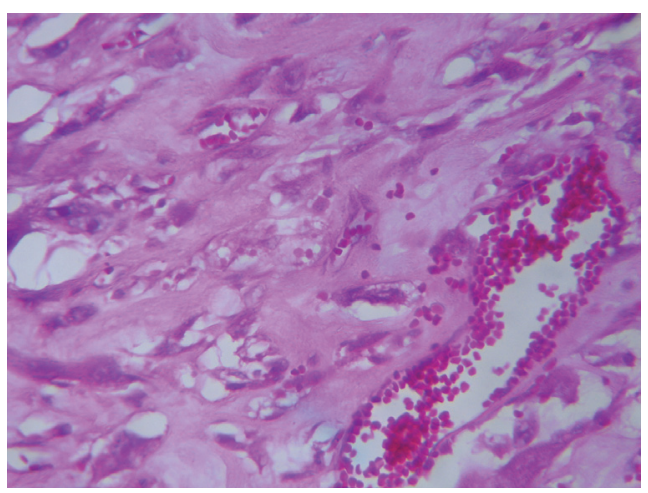

Figure 3. Vascular channels lined by atypical endothelial cells (HE stain, 400).

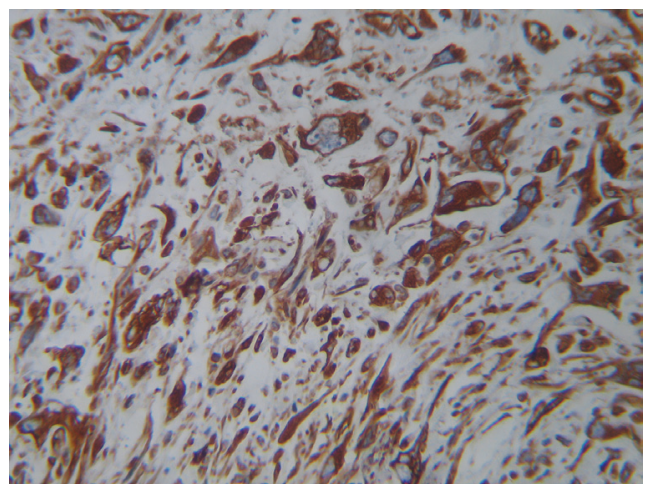

Figure 4. Immunoreactivity for endothelial marker: CD34 immunostain x 200 .

Facor VIII related antigen and immunonegativity for epithelial markers including pancytokeratin, epithelial membrane antigen and thyroglobulin.

Radiotherapy was applied. The patient was alive after a follow up of five months.

\section{Discussion}

Angiosarcoma is uncommon soft tissue neoplasm that ac- count for less than $1 \%$ of all sarcoma. Angiosarcoma involving thyroid is a rare entity, more often described in the Alpine region [3]. The location in the thyroid gland is nevertheless quite exceptional.

The sex distribution was female predominant (femalemale ratio 9:3), the age at diagnosis ranging from 50 to 88 years. The typical history is a sudden and rapid increase in the size of long standing goitre. Common signs and symptoms besides the neck swelling include hoarseness, radiation pain, dysphagia, and marked loss of weight. The presence of goitre was stated in our patient. Progression into the mediastinum with compressive complications has also been described [4].

The tumour ranges in size from 2.5 to $11 \mathrm{~cm}$ and generally occurs singly. The cut surface of the thyroid shows a well demarcated bulging, variated and hemorrhagic dark red lesion.

On histologic examination, this tumour typically discloses anastomosing capillary-sized or dilated spaces lined by large, atypical endothelial cells and containing red blood cells. The endothelial differentiation is shown by immunoreactivity for endothelial markers such as CD31, CD34, Ulex europaeus, factor VIII related-antigen and immunonegativity for epithelial markers including pancytokeratin, epithelial membrane antigen and thyroglobulin. However, a rare aberrant expression of cytokeratin in angiosarcoma in other organs has occasionally been reported because embryonic endothelial cells may express keratin $[5,6]$.

Very often, the tumour shows a well developed fibrous capsule, as seen in our case with remnants of thyroid follicles scattered among the tumour tissue and compressed against the capsule. These features strongly suggest that the tumour has developed on top of goitrous nodule or an adenoma.

The diagnosis is mostly difficult and the histological features mimicking anaplastic carcinoma of the thyroid and other sarcoma.

Focal solid undifferentiated areas are invariably present consisting of spindle cells arranged in fascicular pattern reminiscent of the most common morphologic pattern encountered in an anaplastic carcinoma [7,8]. This latter feature make many experienced pathologists unfamiliar with this lesion to regard it as a variant of anaplastic carcinoma or other sarcoma. In such circumstances, angiosarcoma can be distinguished from it by immunohistochemistry. To date, CD31 is considered the most sensitive and specific marker for endothelial differentiation, being expressed in $90 \%$ of angiosarcoma and in less than $1 \%$ of carcinomas $[3,9]$.

Its etiology remains unknown. The prognosis of this tumour is worst because it is growing very fast and can develop metastases. These are found most frequently in the lungs and cervical or thracheobronchial lymph nodes [1].

Therapy is a challenge with frequent difficulties. Surgery represents the first step of choice in cases of radically removable tumour as seen in our patient. Radiation therapy may be effective in some patients and can be completed us- 
ing adriamycin [4].

\section{Conflict of Interest}

No competing interest.

\section{References}

1. Chan YF, Ma L, Boey JH, Yeung HY. Angiosarcoma of the thyroid. An immunohistochemical and ultrastructural study of a case in a Chinese patient. Cancer 1986;57(12):2381-2388.

2. Kim NR, Ko YH, Sung CO. A case of coexistent angiosarcoma and follicular carcinoma of the thyroid. J Korean Med Sci 2003;18(6):908-913.

3. Goh SG, Chuah KL, Goh HK, Chen YY. Two cases of epithelioid angiosarcoma involving the thyroid and a brief review of non-Alpine epithelioid angiosarcoma of the thyroid. Arch Pathol Lab Med 2003;127(2):E70-73.
4. Astl J, Duskova J, Limanova Z, Povysil C, Kuchynkova Z. Hemangiosarcoma of the Thyroid Gland. A case report. Neuro Endocrinol Lett 2000;21(3):213-216.

5. Eusebi V, Carcangiu ML, Dina R, Rosai J. Keratinpositive epithelioid angiosarcoma of thyroid. A report of four cases. Am J Surg Pathol 1990;14(8):737-747.

6. Miettinen M, Fetsch JF. Distribution of keratins in normal endothelial cells and a spectrum of vascular tumors: implications in tumor diagnosis. Hum Pathol 2000;31(9):1062-1067.

7. Papotti M, Arrondini M, Tavaglione V, Veltri A, Volante M. Diagnostic controversies in vascular proliferations of the thyroid gland. Endocr Pathol 2008;19(3):175-183.

8. Mills SE, Gaffey MJ, Watts JC, Swanson PE, Wick MR, LiVolsi VA, Nappi O, et al. Angiomatoid carcinoma and 'angiosarcoma' of the thyroid gland. A spectrum of endothelial differentiation. Am J Clin Pathol 1994;102(3):322-330.

9. Lamovec J, Zidar A, Zidanik B. Epithelioid angiosarcoma of the thyroid gland. Report of two cases. Arch Pathol Lab Med 1994;118(6):642-646. 